\title{
AiMT
}

Advances in Military Technology

Vol. 15, No. 2, 2020, pp. 379-391

ISSN 1802-2308, eISSN 2533-4123

DOI 10.3849/aimt.01427

\section{Experimental and Numerical Modal Analysis of the Military Vehicle Hull}

\author{
Z. Hryciów, A. Wiśniewski ${ }^{*}$ and P. Rybak \\ Faculty of Mechanical Engineering, Military University of Technology, Warsaw, Poland
}

The manuscript was received on 9 June 2020 and was accepted after revision for publication as research paper on 1 November 2020.

\begin{abstract}
:
This paper presents an experimental and numerical modal analysis of the military vehicle hull. Due to its adaptation to various weapon systems, it is necessary to conduct detailed tests. Computer simulations are a very useful tool. To ensure the reliability of the results, it is necessary to validate the models. The modal analysis was used in this work. It was carried out using the roving hammer method. Both natural frequency and mode shape were compared. The Modal Assurance Criterion was used for the comparison. To determine areas of noncompliance, distributions of relative differences between experimental and finite element (FE) mode shapes were prepared. The presented results indicate a large convergence between the results of numerical and experimental analyses.
\end{abstract}

\section{Keywords:}

military vehicle, modal analysis, roving hammer, vibration

\section{Introduction}

Modern armoured vehicles, especially for special purposes, play different roles on the battlefield. Their design, equipment and performance are determined by the intended purpose. Armoured vehicles can be used as infantry carriers, direct fire support vehicles, reconnaissance vehicles, technical recovery vehicles and others. During their construction, modular conception is used which enables the implementation of versions adapted to various tasks.

The universality of the structure brings additional requirements that must be met by the base structure. Various applications / installed weapon systems generate different values of loading to a hull, suspension, running gear and propulsion systems.

\footnotetext{
* Corresponding author: Faculty of Mechanical Engineering, Military University of Technology, gen. Sylwestra Kaliskiego 2 St., Warsaw PL 00-908, Poland. Phone:+48 261837 364, E-mail: wisniewski.andrzej@wat.edu.pl,ORCID 0000-0002-2089-1942
} 
Therefore, before making a decision to change the purpose of an armoured vehicle, it is necessary to conduct appropriate tests.

A common practice used by scientific and research centres during designing and developing new constructions is the numerical approach using the finite element (FE) method. FE analysis has become an essential tool to estimate structural responses under static and dynamic loads. Research is being conducted [1,2] to determine the exposure of crew and specialist equipment to such threats as direct fire, anti-tank mine explosion and improvised explosive devices. This approach allows the development of solutions to improve their protection [3-5], as well as optimization of its parameters to minimize the crew's exposure to threats as much as possible. An important aspect in the design process is also fulfilment of international requirements for ensuring an adequate degree of protection contained in standards such as NATO STANAG 4569.

Numerical methods allow for a wide range of analysis, e.g. the impact of various equipment configuration variants and armour on the crew and equipment protection level, as well as traction and operational properties. The undoubted advantage of this method when having the right data, compared to testing of real objects, is a significant cost reduction, identification of sensitive construction nodes along with determination of resonance frequencies that can have a big impact on the durability and reliability of specialized equipment.

To ensure the reliability of research results it is necessary to validate the numerical model. A different approach is presented in the literature in this regard. The best way how to achieve the highest reliability is to conduct experimental research on real objects on a full scale. Unfortunately, such tests are costly and, with respect to the tests required for armoured vehicles, they often lead to structural damage. Another approach is to conduct research using substitute models or separate parts of the structure. However, they do not always allow correct mapping of the entire vehicle structure behaviour.

Valuable information on dynamic properties of technical objects is provided by modal analysis. This method is applied in numerous fields of technology. It also allows validation of numerical models. This approach is presented, among others in $[6,7]$ where the authors presented the use of modal analysis in the study of the entire hull of a combat vehicle as well as fragments of protective structures. In [8], the dynamic properties of a steel plate are investigated using FE model and experimental method. The FE model was validated using modal testing. In [9], a method of refining of the numerical model based on experimental research is presented. Standard test methods were applied, resulting in satisfactory compliance of the numerical model with the examined object. A similar approach is presented in [10] where the authors presented the bell model validation procedure.

The literature presents examples of the use of modal analysis to assess wear and fatigue. In [11], the experimental modal analysis was carried out on different types of friction stir spot welded specimens after different fatigue life tests. FE modelling was performed in commercial software using the Lanczos method to compare the obtained results with the experimental tests.

The authors [12] presented the application of determining the dynamic characteristics of aircraft propeller, noise generated and the impact of vibration on flight characteristics. The paper [13] presents an operational modal analysis of a stacker operating in a brown coal mine. The results obtained in this way were compared with a numerical experiment. Modal analysis can also be used in the diagnostics of machines or building structures [14]. 
In [15], the use of modal impact testing to characterize the modal properties of a military tactical wheeled vehicles chassis was studied. The results suggest that modal impact testing on ground vehicles is a feasible means of identifying the operational deflection shapes and certain types of mechanical damage.

In this paper, model validation was carried out based on the results of modal analysis. The natural frequencies and mode shape of vibrations have been determined for both the real hull of the vehicle and its numerical model. Particularly important from the authors' point of view is the bottom plate in the crew compartment. It is a vulnerable, unprotected hull fragment characterized by high susceptibility. During normal operation, vibrations are induced in it. This creates additional exposure for soldiers who keep their feet directly on it. Additionally, in the case of detonation of an explosive charge under the bottom it undergoes large dynamic deflections.

The main purpose of the work was to obtain data on natural frequencies and mode shape of vibration of the bottom plate of a military vehicle's hull, followed by validation of a numerical model. An additional goal was to check the possibility of using the interpolation procedure to compare the results of experimental and numerical tests in which a different number of measuring points is used. In this paper, a detailed comparison of results of experimental modal testing and FE model is presented.

\section{Experimental Test}

In the study, modal analysis was used to identify the important dynamic properties of the object. This standard method allows to determine the natural frequencies and normal modes of vibration, as well as to determine the damping coefficients of objects with a complex structure. The special vehicle hull is shown in Fig. 1.

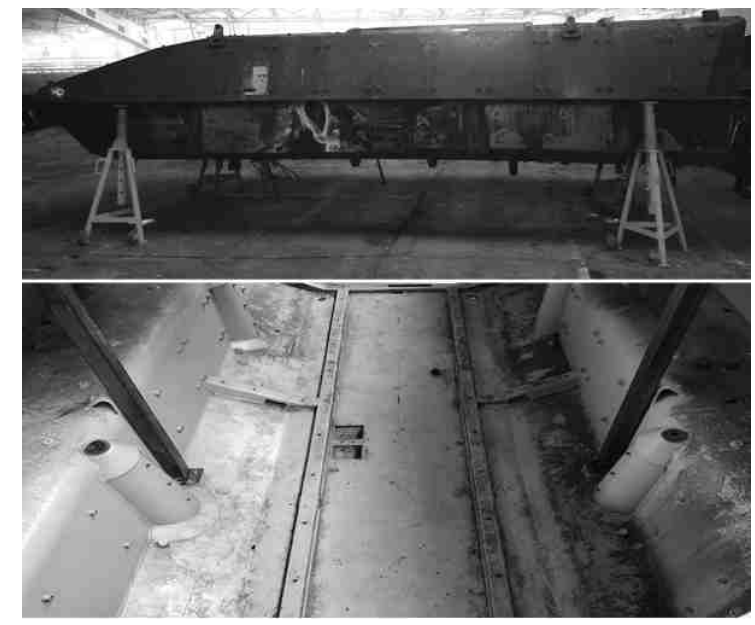

Fig. 1 View of the test object

During modal testing, B\&K modal hammer type 8202 and ICP accelerometers B\&K type 4395 were used. The measuring and recording system consisted of an 8-channel Sirius+ vibration analyser and a computer with Dewesoft X3 software. 91 measuring points were determined on the hull's bottom plate, which were excited by a modal hammer. The response of the tested object was measured by seven accelerometers, in a configuration shown in Fig. 2. In the scheme, the green points indicate 
places of hammer impact, while the red-green ones points where accelerometers were mounted (on the opposite side of the plate - outside of the vehicle).

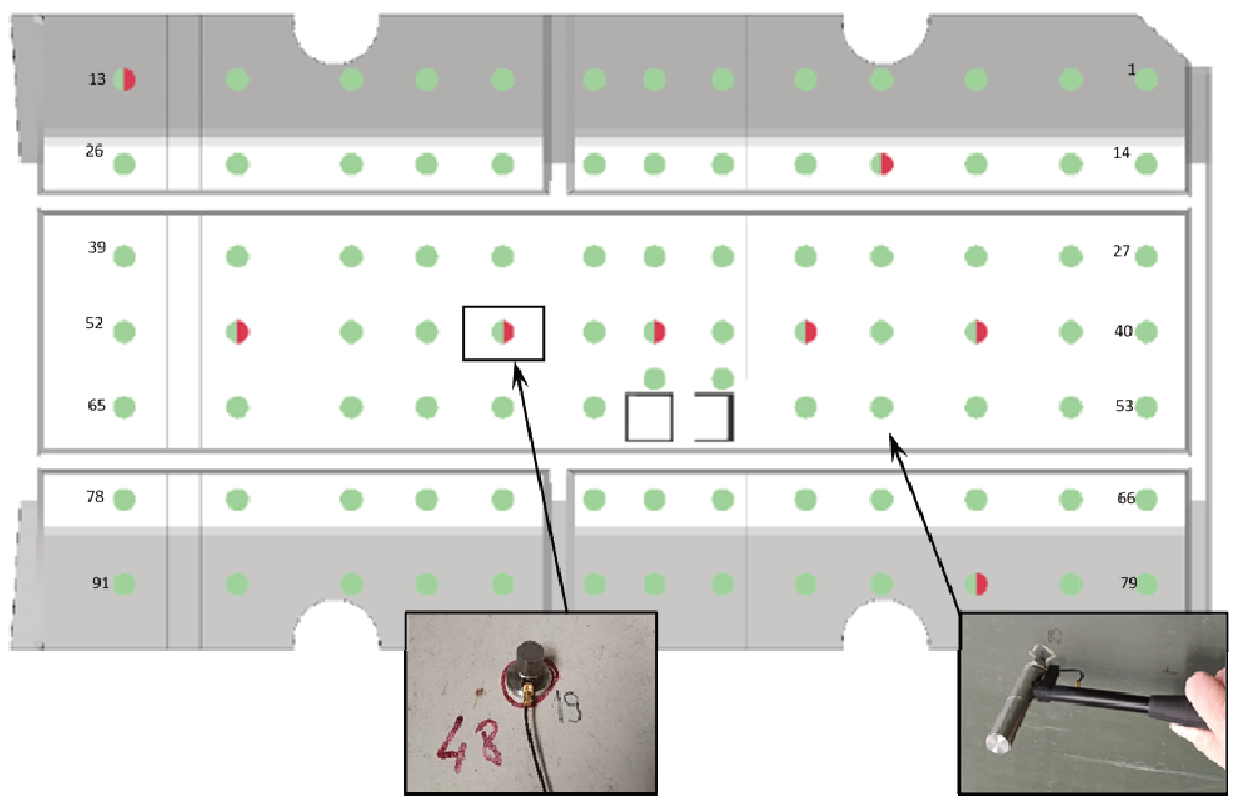

Fig. 2 Measuring point grid and location of accelerometers

The roving hammer method was applied during the measurements, in which response measurement point was fixed, and the hammer was roved over the entire structure. In the series of tests, the impact forces were evaluated on the basis of trigger level, double hit level and overload level. The result has been improved by averaging the excitation and response spectra over a number of impacts ( 3 hits were recognized and taken into calculation). Example of excitation and response is presented in Fig. 3.
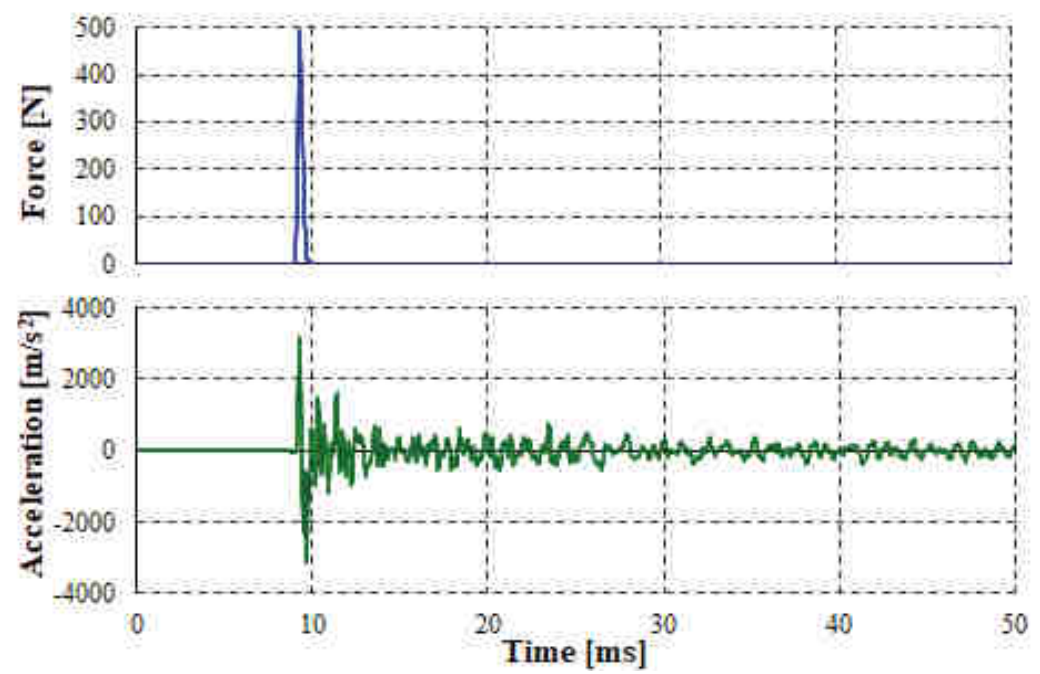

Fig. 3 Example of excitation and response 
The Dewesoft X3 software system recorded and analysed the excitation and response of the structure in selected nodes in real time and calculated it the transfer functions described by formula (H1 estimator is used):

$$
T F(\omega)=\frac{S_{x y}(\omega)}{S_{x x}(\omega)}
$$

where $S_{x y}(\omega)$ is the Cross Spectral Density in the frequency domain of input $X(t)$ (force) and output $Y(t)$ (acceleration), $S_{x x}(\omega)$ is the Auto Spectral Density in the frequency domain of input $X(t)$ (force).

The H1 $(\omega)$ estimator is used in situations where the output to the system is expected to be noisy when compared to the input. The function was determined for each pair (impact-response) to obtain 637 transfer functions for the examined object. When the amplitude of the transfer function shows a local maximum, and the phase is turning in this point, it usually indicates a resonance. To be sure, also the coherence should be checked. And last, Mode Indicator Function (MIF) was calculated. It could be found using the following Eq. (2):

$$
\mathrm{MIF}=1-\frac{\sum_{i, j=1}^{n} \operatorname{Real}\left[T F_{i j}(\omega)\right] \cdot\left|T F_{i j}(\omega)\right|}{\sum_{i, j=1}^{n}\left|T F_{i j} T F_{i j}(\omega)\right|^{2}}
$$

MIF value close to 1 indicates a mode shape. MIF is a vector channel, and it is calculated over all transfer functions (all points), therefore it is only one channel. Fig. 4 shows a graph of the MIF function calculated based on transfer functions. The points for which subsequent natural frequencies were observed were marked on it.

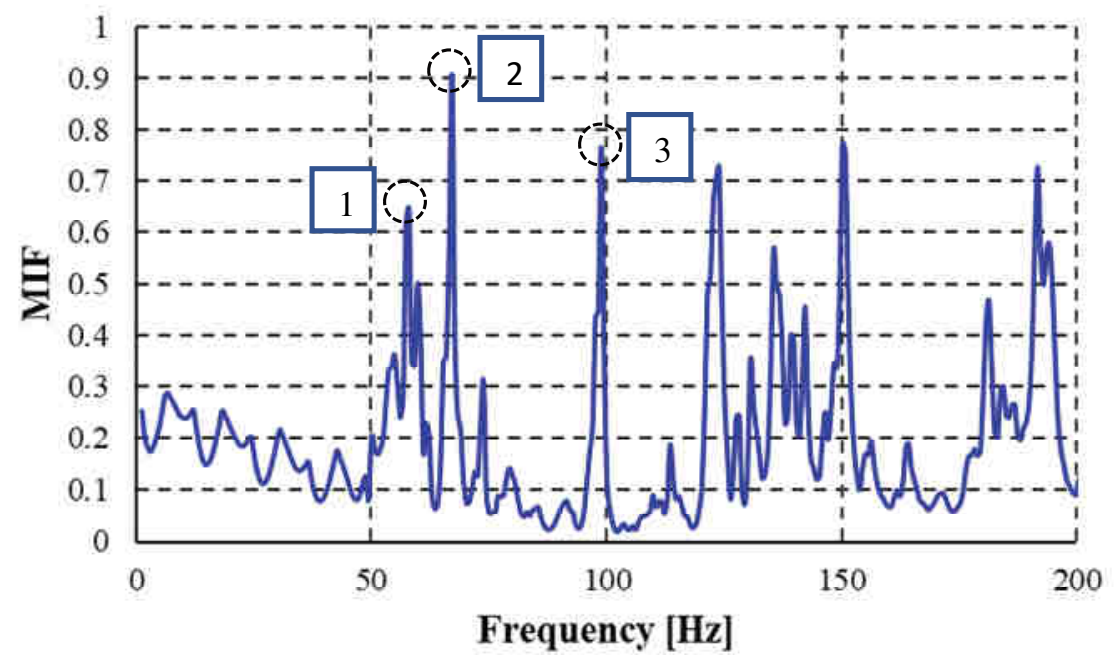

Fig. 4 A graph of the MIF function

To compare results of simulations and experiment tests, Natural Frequency Difference (NFD) correlation coefficient described in Eq. (3) was used. It gives an assessment of the difference between the natural frequencies of a pair of modes in two modal data sets. 


$$
\operatorname{NFD}\left(e_{i}, s_{j}\right)=\frac{\left|\left(\omega_{e}\right)_{i}-\left(\omega_{s}\right)_{j}\right|}{\min \left[\left(\omega_{e}\right)_{i},\left(\omega_{s}\right)_{j}\right]} \cdot 100 \%
$$

In the formula, $\left(\omega_{e}\right)_{i}$ is the natural frequency of $i^{\text {th }}$ mode in an experimental data set, and $\left(\omega_{s}\right)_{j}$ is the natural frequency of the $j^{\text {th }}$ mode in simulation data set.

Modal Assurance Criterion (MAC) was used to provide an overall estimation of the difference between two mode shapes. It can be given as Eq. (4):

$$
\operatorname{MAC}(i, j)=\frac{\left|\left\{\boldsymbol{\Psi}_{\boldsymbol{e}}\right\}_{i}^{\mathrm{T}}\left\{\boldsymbol{\Psi}_{\boldsymbol{s}}\right\}_{j}\right|^{2}}{\left(\left\{\boldsymbol{\Psi}_{\boldsymbol{e}}\right\}_{i}^{\mathrm{T}}\left\{\boldsymbol{\Psi}_{\boldsymbol{e}}\right\}_{i}\right)\left(\left\{\boldsymbol{\Psi}_{s}\right\}_{j}^{\mathrm{T}}\left\{\boldsymbol{\Psi}_{s}\right\}_{j}\right)}
$$

where $\boldsymbol{\Psi}_{e}$ is mode shape vector from experimental test, $\boldsymbol{\Psi}_{s}$ mode shape vector from $\mathrm{FE}$ analysis.

Using this criterion, the modal vectors from a finite element analysis can be compared with those determined experimentally, as well as with modal vectors determined by way of different experimental or modal parameter estimation methods. MAC value of 0 means that the two-mode-shapes are completely different in shape. MAC value of 1 indicates that the two-mode-shapes have the same shape. In practice [16], two vectors are considered correlated when MAC is greater than 0.9 , while they are judged uncorrelated when the MAC is lower than 0.6.

MAC criterion allows for comparison of two-mode shapes, however, it does not provide information in which areas the compared vectors are different. In order to show areas of noncompliance, distributions of differences between vertical displacements of individual nodes obtained in experimental and numerical studies were computed. Both vectors were normalized before comparison. Due to the different number and coordinates of nodes in experimental (91) and simulation (10 800) tests, it is necessary to adapt two meshes to equal dimensions. It was decided to use the interpolation procedure adapting the mesh from experimental to simulation studies. Cubic interpolation was used to determine the values at additional points. This approach is different from those presented in the literature.

\section{Numerical Test}

A numerical model was developed to determine the modal frequency and the mode shape of the hull vibration. It contains about 145 thousand shell elements. Besides the hull plates, all reinforcements, equipment mounting brackets plus bulkheads located inside the hull were taken into account. All these elements affect the change of hull stiffness and thus its vibration. The vehicle hull model is shown in Fig. 5.

LS-DYNA software was used for the modal analysis of the hull structure. Due to the large number of degrees of freedom of the analysed structure, the calculation uses the iterative Lanczos algorithm, adapted to search for a predetermined number from many eigenvalues. During the calculations, 50 lowest natural frequencies were determined, as well as mode shape of vibration of the hull structure. The formulated problem requires the solution of the equation of state describing the generalized eigenvalue problem, which in matrix form has the form (5):

$$
\left(\boldsymbol{K}-\boldsymbol{M} \omega_{0}^{2}\right) \cdot \boldsymbol{\Psi}=0
$$




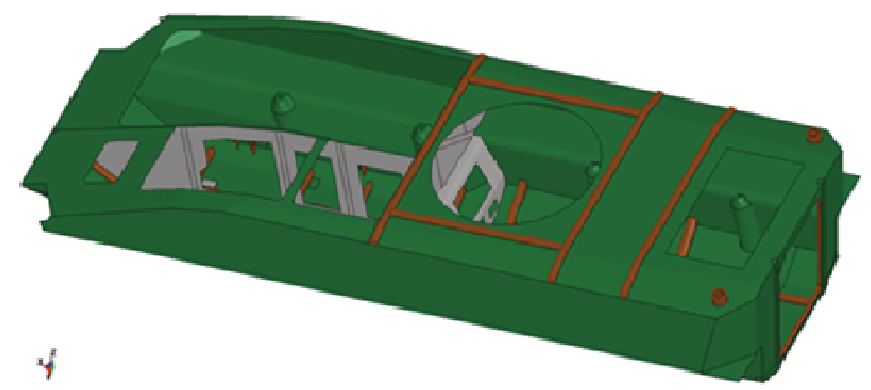

Fig. 5 The vehicle hull model

where $\boldsymbol{\omega}_{\mathrm{o}}$ - the natural frequencies vector, $\boldsymbol{\Psi}$ - the mode shape vector, $\boldsymbol{K}$ - the stiffness matrix of the system, $\boldsymbol{M}$ - the inertia matrix.

From the point of view of the work being carried out, vibrations of the bottom plate located in the crew compartment are the most interesting. Due to the coupling between the bottom and the side walls, it is not possible to extract the bottom itself for calculations. This results in the introduction of different boundary conditions on the edges, which significantly changes both natural frequencies and mode shape of vibrations.

Fig. 6 presents an example illustrating the impact of boundary conditions on natural frequencies and mode shape of the bottom plate of the crew compartment. Calculations were made for a free plate (Fig. 6a) and the one fixed on its edge (Fig. 6b). Fig. 6c shows the calculation of the obtained results for the entire hull. For ease of comparison with the previous ones, Fig. 6d shows only the bottom fragment. $53.18 \mathrm{~Hz}$ is the lowest natural frequency associated with the bottom plate only. Of course, there are also lower ones, but they are associated with the natural vibrations of the hull as a whole (mainly bending and torsion of the hull in various planes). Based on the obtained results, it can be clearly stated that calculations cannot be made for the bottom plate alone. In order to correctly map its working conditions, it is necessary to include a whole hull in the calculations.

a) $\mathrm{f}_{0}-17.31 \mathrm{~Hz}$

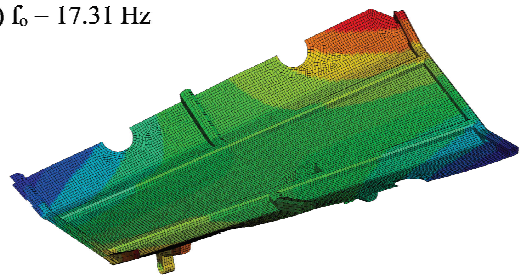

b) $\mathbf{f}_{0}-98.46 \mathrm{~Hz}$

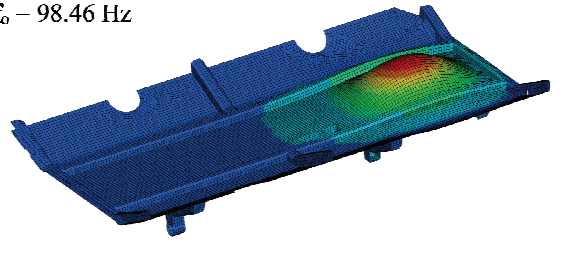

c) $\mathrm{C}_{0}-53.18 \mathrm{~Hz}$

d) $\mathrm{f}_{\mathrm{o}}-53.18 \mathrm{~Hz}$

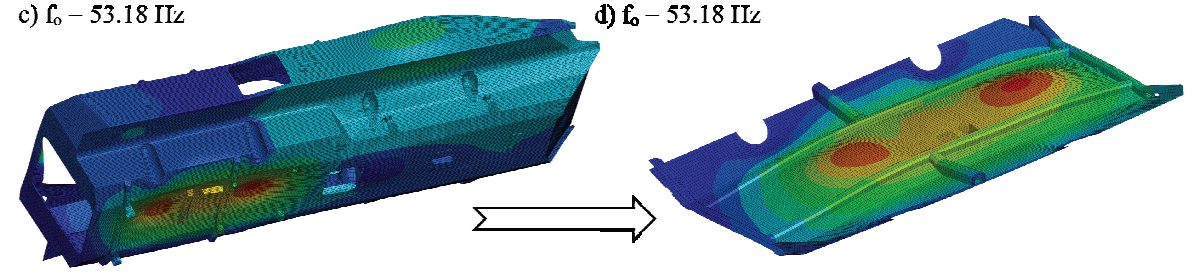

Fig. 6 Natural frequencies and mode shape of vibrations: a) free plate, b) plate fixed on its edge, c) whole hull, d) bottom plate 


\section{Results and Discussion}

In accordance with the methodology presented in Chapters 2 and 3, measurements and modal analysis of the hull's bottom plate vibrations were carried out. These data were used to perform a comparative analysis with the results of numerical analysis.

In order to compare a similarity between the mode shape obtained during numerical simulation, an autoMAC analysis was carried out (MAC analysis within a single mode set). In the case of vibrations of a single element, an autoMAC takes the form of a diagonal matrix. However, the considered bottom is only a fragment of a larger structure and the vibrations of each plates of the hull are strongly coupled with each other. Modal coupling is a general term used to indicate how much of the response, at one modal frequency, is influenced by contributions from other modes. This phenomenon can be observed in Fig. 7 which shows non-zero values beyond the main diagonal. It means that we do not observe clearly distinctive modes and the response at any frequency is a combination of many modes.

To assess the accuracy of the FE model, the first 4 natural frequencies and mode shapes were extracted from the analysis and compared to the experimental results. The results are summarized in Tab. 1. The natural frequency predicted by the FE model for the first mode is approximately $9 \%$ lower than that observed in the experiment.

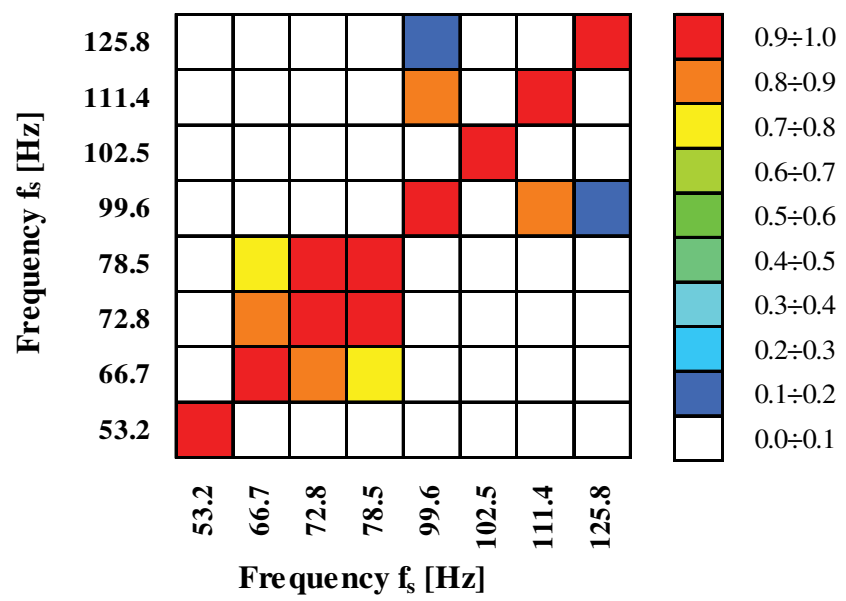

Fig. 7 AutoMAC - simulation results

Mode 2 shows similar natural frequency correlation, while mode 4 has the smallest relative difference $(1.89 \%)$.

Tab. 1 Natural frequencies

\begin{tabular}{|c|c|c|c|}
\hline $\begin{array}{c}\text { Mode } \\
\text { Shape } \\
\text { No }\end{array}$ & \multicolumn{2}{|c|}{ Natural frequency $[\mathrm{Hz}]$} & \multirow{2}{*}{$\begin{array}{l}\text { NFD } \\
{[\%]}\end{array}$} \\
\cline { 2 - 3 } & Experiment & FE model & \\
\hline 1 & 57.98 & 53.18 & 9.03 \\
\hline 2 & 67.14 & 72.81 & 8.45 \\
\hline 3 & 98.27 & 102.5 & 4.30 \\
\hline 4 & 113.5 & 111.4 & 1.89 \\
\hline
\end{tabular}


For the considered bottom plate of vehicle hull, a few lowest mode shapes are the most important. For real objects, first mode shapes may have significant impact on structure response exposed to both for short and long term excitations [17]. Similar behaviour based on experimental studies was found in [7] for a vehicle structure loaded with explosive wave. Moreover, the first mode is considered the most important metric for accurate structural response prediction. For this reason, it is important to reduce the model prediction error as much as possible to match the experiment. For the developed model satisfactory compatibility with the experiment results was achieved.

The mode shape comparison between the experiment, its interpolation and numerical simulation is shown in Fig. 8. For an easier comparison, the results of experimental studies were presented using a colour scale as in the numerical studies. The four lowest frequencies of natural vibrations closely related to the vibrations of the bottom plate were taken for comparison. Certainly, other resonance frequencies were also observed during the study, but they were associated with the hull's vibration as a whole (including the side walls). The results presented below clearly indicate a large convergence between the results of numerical and experimental analyses.

The quantitative indicator of the similarity of the vibrations obtained experimentally and numerically is the MAC criterion. For all mode shapes the MAC reach a value greater than 0.9 (Fig. 9). This indicates a very high degree of similarity.

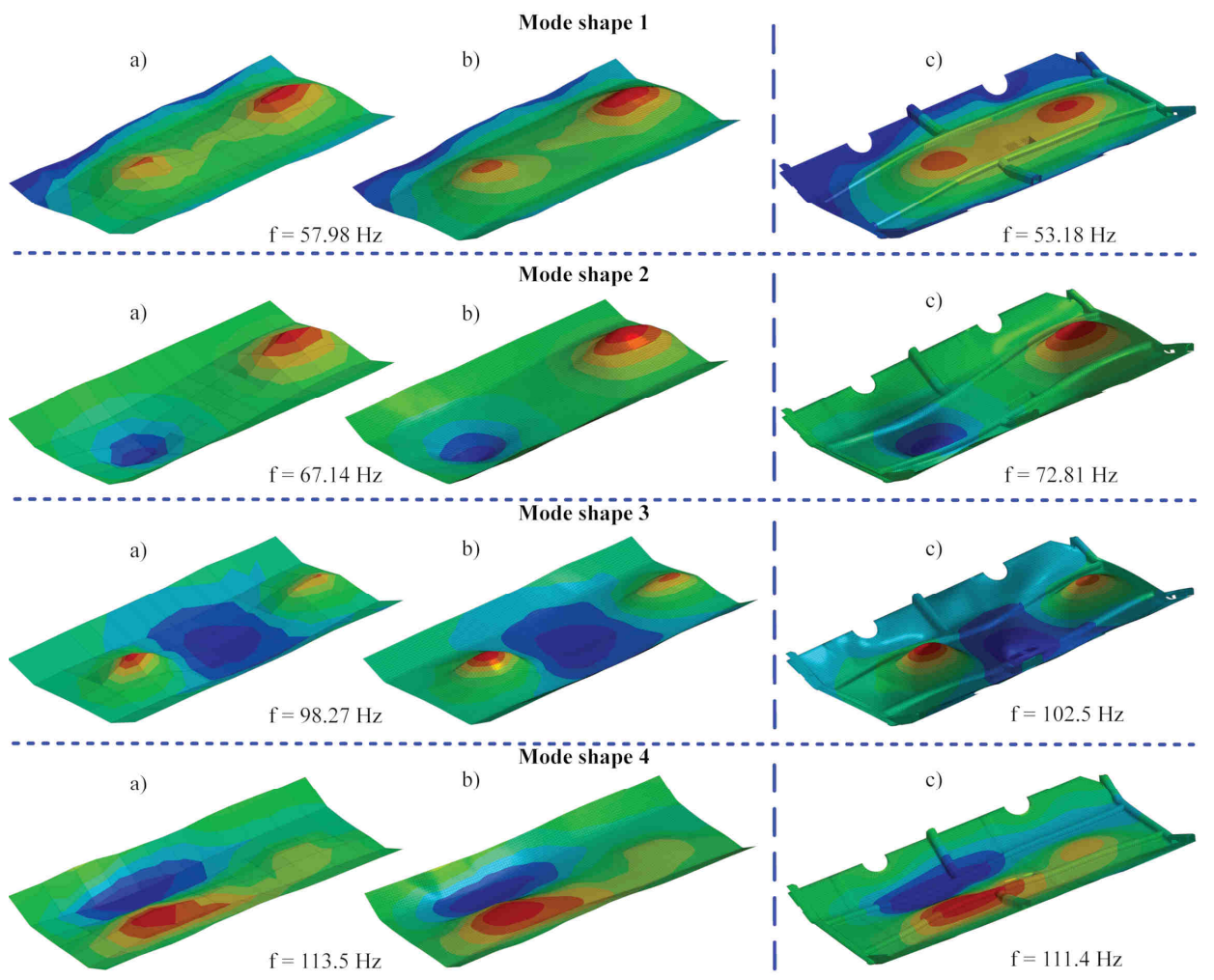

Fig. 8 Mode shape comparison between the FE model and the experiment: a) experiment, $b$ ) interpolated from experiment, $c$ ) numerical simulation 
In order to show areas of noncompliance, distributions of differences between vertical displacements of individual nodes obtained in experimental and numerical studies were computed. Based on these distributions (Fig. 10, Tab. 2), it should be stated that the maximum discrepancies between simulation results and experimental tests do not exceed 33\% (third mode shape). However, in most areas of the plates they do not exceed $10 \%$. The smallest disagreements were obtained for second mode shape.

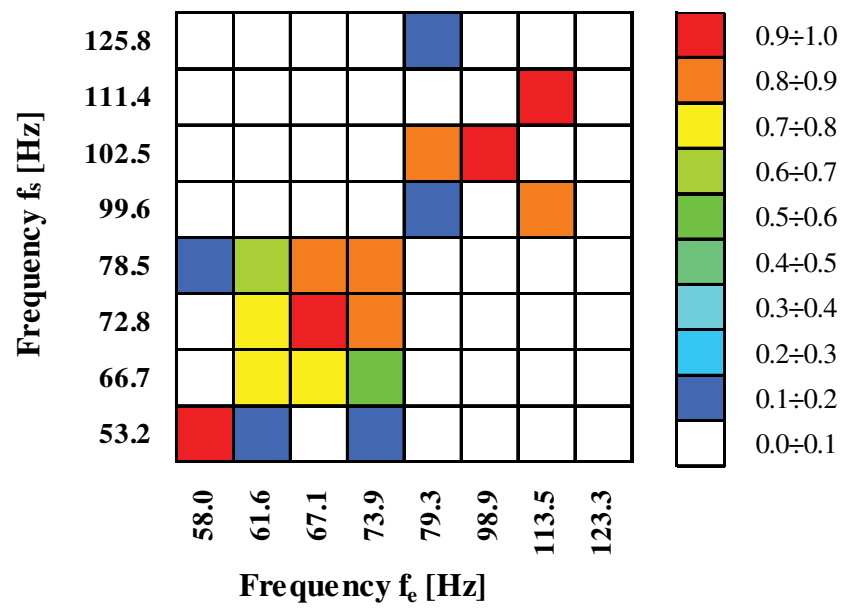

Fig. 9 MAC matrix

Tab. 2 Natural frequencies

\begin{tabular}{|c|c|c|c|}
\hline \multirow{2}{*}{$\begin{array}{l}\text { Mode } \\
\text { Shape } \\
\text { No }\end{array}$} & \multicolumn{2}{|c|}{ Difference } & \multirow{2}{*}{ MAC } \\
\cline { 2 - 3 } & $\min$ & $\max$ & \\
\hline 1 & -23.73 & 24.13 & 0.967 \\
\hline 2 & -14.15 & 11.58 & 0.972 \\
\hline 3 & -33.61 & 13.52 & 0.919 \\
\hline 4 & -29.69 & 32.82 & 0.945 \\
\hline
\end{tabular}

\section{Conclusions}

This paper presented both the experimental and numerical methods to determine the modal characteristics of a military vehicle hull. A modal test system was constructed to perform the bottom plate's natural frequency measurement through the 'roving hammer' impact technique.

The measured natural frequencies and the FE method results showed an appropriate correlation. A maximum $9 \%$ discrepancy on the natural frequencies was achieved for a mode shape 1 while for the others the differences were smaller.

The MAC method is very useful for comparison of mode shapes vectors. For all mode shapes, the MAC reaches a value greater than 0.9 . This indicates a very high degree of similarity. 


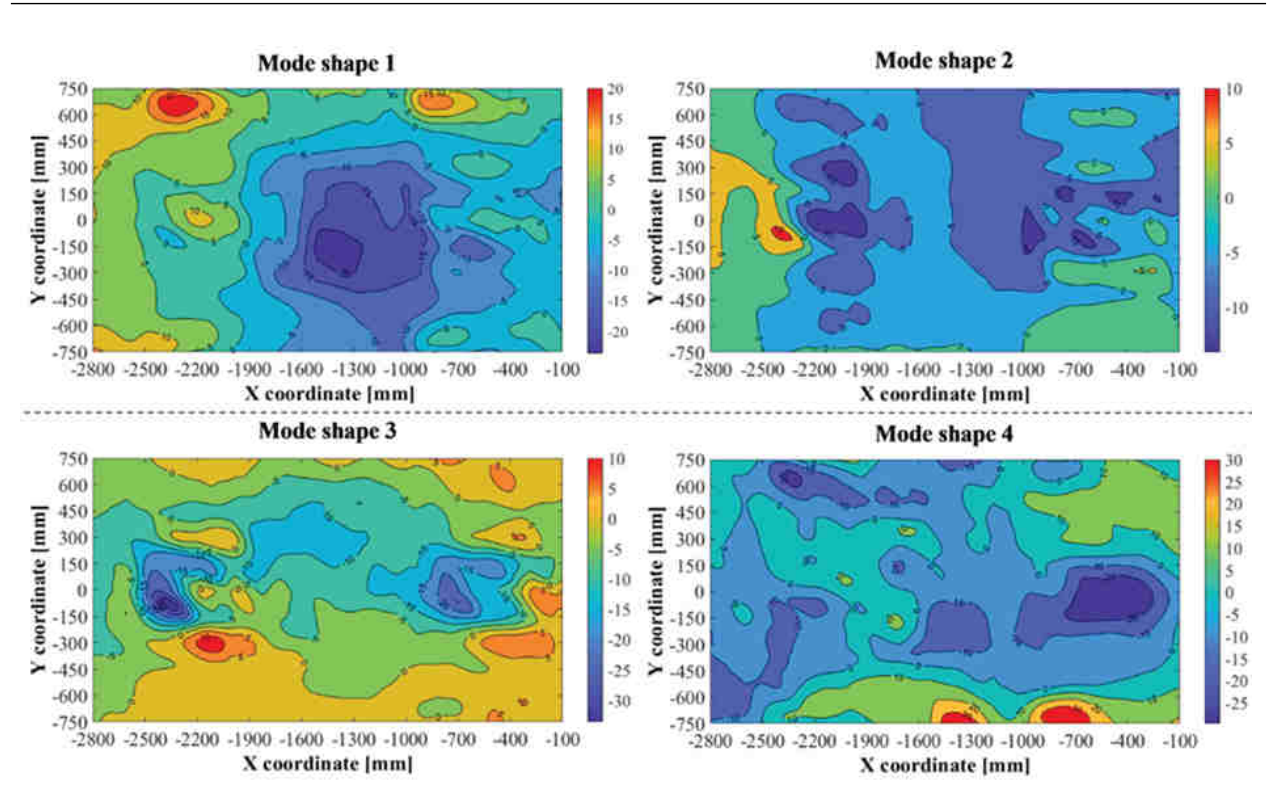

Fig. 10 Distributions of mode shapes differences between the FE model and the experimental test

Distributions of relative differences between experimental and FE mode shapes indicate the places of noncompliance, and as a consequence, they enable the improvement of the model. In most areas of the plate, the differences do not exceed $10 \%$.

For a realistic solution, the validation of FE model in terms of its modal properties, such as natural frequencies, mode shapes and response is necessary along with basic checks of FE model in terms of its mass and stiffness distribution. The experimental modal testing is one of the methods for validation of FE models.

\section{Acknowledgement}

The scientific article was financed by the Ministry of Science and Higher Education from a special purpose grant for the maintenance and development of young scientists.

\section{References}

[1] MACKIEWICZ, A., SŁAWIŃSKI, G., NIEZGODA, T. and BĘDZIŃSKI, R. Numerical Analysis of the Risk of Neck Injuries Caused by IED Explosion under the Vehicle in Military Environments. Acta Mechanica et Automatica, 2016, vol. 10, no. 4, p. 258-264. DOI 10.1515/ama-2016-0039.

[2] SUHAIMI, K., RISBY, M.S., TAN, K.S. and KNIGHT, V. Simulation on the Shock Response of Vehicle Occupant Subjected to Underbelly Blast Loading. Procedia Computer Science, 2016, vol. 80, p. 1223-1231. DOI 10.1016/j.procs. 2016.05.488.

[3] MIKULIC, D. Design of Demining Machines. London: Springer, 2013, 228 p. ISBN 978-1-44-714503-5. 
[4] PARK, C.Y. Numerical Study on Determining Design Parameters of Wheeled Armored Vehicles. Journal of Mechanical Science and Technology, 2017, vol. 31, no. 12, p. 5785-5799. DOI 10.1007/s12206-017-1121-1.

[5] RYBAK, P.A. Shaping the Impact Resistance of the Supporting Structures of Combat Vehicles (in Polish). Warsaw: Wojskowa Akademia Techniczna, 2013, 224 p. ISBN 978-8-36-295487-2.

[6] MORRIS, B. Modal Analysis of the Prototype Heavy Composite Hull. Harrow: Storming Media, 1998, 116 p. ISBN 978-1-42-356584-0.

[7] HOWLE, D., KRAYTERMAN, D., PRITCHETT, J.E. and SORENSON, R. Validating a Finite Element Model of a Structure Subjected to Mine Blast with Experimental Modal Analysis [online]. Adelphi: U.S. Army Research Laboratory, 2017, 42 p. [viewed 2020-03-02]. Available from: https://www.hsdl.org/? abstract\&did $=814534$

[8] REZA ASHORY, M. and JAMSHIDI, E. Comparison of FE and Modal Models in Model Updating Methods [online]. In Proceedings of the $14^{\text {th }}$ International Congress on Sound and Vibration. Cairns, 2007, 8 p. [viewed 2020-03-26]. Available from: https://www.acoustics.asn.au/conference_proceedings/ICSV14/ papers/p675.pdf

[9] LUCZAK, M., MANZATO, S., PEETERS, B., BRANNER, K., BERRING, P. and KAHSIN, M. Updating Finite Element Model of a Wind Turbine Blade Section Using Experimental Modal Analysis Results [online]. Shock and Vibration, 2014, vol. 2014, Article ID 684786. [viewed 2020-04-19]. Available from: https://www.hindawi.com/journals/sv/2014/684786/

[10] SIEBERT, A., BLANKENHORN, G. and SCHWEIZERHOF, K. Investigating the Vibration Behavior and Sound of Church Bells Considering Ornaments and Reliefs Using LS-DYNA [online]. In Proceedings of the $9^{\text {th }}$ International LSDYNA Conference. Detroit, 2006, 12 p. [viewed 2020-02-06]. Available from: https://www.dynalook.com/conferences/international-conf-2006/21Simulation Technology.pdf

[11] AGHDAM, N.J., HASSANIFARD, S., ETTEFAGH, M.M. and NANVAYESAVOJBLAGHI, A. Investigating Fatigue Life Effects on the Vibration Properties in Friction Stir Spot Welding Using Experimental and Finite Element Modal Analysis. Journal of Mechanical Engineering, 2014, vol. 60, no. 11, p. 735-741. DOI 10.5545/sv-jme.2013.1324.

[12] KILIKEVIČIUS, A., RIMŠA, V. and RUCKI, M. Investigation of Influence of Aircraft Propeller Modal Parameters on Small Airplane Performance. Maintenance and Reliability, 2020, vol. 22, no. 1, p. 1-5. DOI 10.17531/ ein.2020.1.1.

[13] RUSIŃSKI, E., CZMOCHOWSKI, J. and PIETRUSIAK, D. Problems of Steel Construction Modal Models Identification [online]. Maintenance and Reliability, 2012, vol. 14, no. 1, p. 54-61. [viewed 2020-02-12]. Available from: http://www.ein.org.pl/sites/default/files/2012-01-07.pdf

[14] ŻÓŁTOWSKI, M. and NAPIERAJ, K. Evaluation of Degradation of Bricks Using FRF. Budownictwo $i$ Architektura, 2017, vol. 16, no. 3, p. 25-36. DOI 10.24358/Bud-Arch_17_163_03. 
[15] MEYER, A., WANG, B., BRITT, S., KAZI, R. and ADAMS, D.E. Modal Impact Testing of Ground Vehicle Enabling Mechanical Condition Assessment. In PROULX, T. (eds). Modal Analysis Topics, Volume 3. Conference Proceedings of the Society for Experimental Mechanics Series. New York: Springer, 2011, p. 93-101. ISBN 978-1-4419-9298-7.

[16] Structural Dynamics Toolbox \& FEMLink [online]. Paris: SDTools, 2019. 903 p. [viewed 2020-03-05]. Available from: https://www.sdtools.com/help/sdt.pdf

[17] HAO, H. Predictions of Structural Response to Dynamic Loads of Different Loading Rates. International Journal of Protective Structures, 2015, vol. 6, no. 4, p. 585-605. DOI 10.1260/2041-4196.6.4.585. 